\title{
Microbiologic and Histologic Characteristics of the Extremely Preterm Infant's Placenta Predict White Matter Damage and Later Cerebral Palsy. The ELGAN Study
}

\author{
ALAN LEVITON, ELIZABETH N. ALLRED, KARL C. K. KUBAN, JONATHAN L. HECHT, ANDREW B. ONDERDONK,
} T. MICHAEL O'SHEA, AND NIGEL PANETH

\begin{abstract}
Department of Neurology, Children's Hospital Boston [A.L., E.N.A.], Department of Pathology, Beth Israel Deaconess Medical Center [J.L.H.], Department of Pathology, Brigham and Women's Hospital [A.B.O.], Harvard Medical School, Boston, Massachusetts 02115; Department of Pediatrics [K.C.K.K.], Boston University, Boston, Massachusetts 02118; Department of Pediatrics [T.M.O.], Wake Forest University School of Medicine, Winston-Salem, North Carolina 27157; Department of Epidemiology [N.P.], Michigan State University,
\end{abstract} East Lansing, Michigan 48824

\begin{abstract}
Inflammatory phenomena seem to contribute to the occurrence of perinatal cerebral white matter damage and $\mathrm{CP}$. The stimulus that initiates the inflammation remains obscure. One thousand two hundred forty-six infants born before the 28th postmenstrual week had a protocol ultrasound scan of the brain read concordantly by two independent sonologists. Eight hundred ninety-nine of the children had a neurologic examination at approximately 24-mo postterm equivalent. The placenta of each child had been biopsied under sterile conditions and later cultured. Histologic slides of the placenta were examined specifically for this study. Recovery of a single microorganism predicted an echolucent lesion, whereas polymicrobial cultures and recovery of skin flora predicted both ventriculomegaly and an echolucent lesion. Diparetic CP was predicted by recovery of a single microorganism, multiple organisms, and skin flora. Histologic inflammation predicted ventriculomegaly and diparetic CP. The risk of ventriculomegaly associated with organism recovery was heightened when accompanied by histologic inflammation, but the risk of diparetic $\mathrm{CP}$ was not. Low-virulence microorganisms isolated from the placenta, including common skin microflora, predict ultrasound lesions of the brain and diparetic $\mathrm{CP}$ in the very preterm infant. Organism recovery does not seem to be needed for placenta inflammation to predict diparetic CP. (Pediatr Res 67: 95-101, 2010)
\end{abstract}

$\mathrm{I}_{\mathrm{a}}^{\mathrm{n}}$ nfants born long before term are at increased risk of motor, attention, cognitive, and executive function impairments (1-3). Some of the increased risk seems to be caused by cerebral white matter damage evident on brain ultrasound scans (4). The damage takes two forms-an echolucent (hypoechoic) lesion (also known as periventricular leukomalacia), considered evidence of focal or multifocal disease, and late ventriculomegaly, considered evidence of diffuse white matter damage.

Received April 30, 2009; accepted August 29, 2009.

Correspondence: Alan Leviton, M.D., Children's Hospital Boston, One Autumn Street, Box 720, Boston, MA 02215; e-mail: alan.leviton@ childrens.harvard.edu

Supported by a grant 5U01NS040069-05 from a cooperative agreement with the National Institute of Neurological Disorders and Stroke and a program project grant NIH-P30-HD18655 from the National Institute of Child Health and Human Development.

Supplemental digital content is available for this article. Direct URL citations appear in the printed text and are provided in the HTML and PDF versions of this article on the journal's Web site (www.pedresearch.org).
Postnatal bacteremia seems to contribute to the occurrence of diffuse white matter damage (5-7) and later neurodevelopmental disabilities (7-9). Because preterm newborns who die with white matter damage very rarely have a microorganism in the brain (10), a circulating, noninfectious messenger originating at the site of microorganism colonization that can then gain access to the brain might account for the brain damage associated with bacteremia (11).

Might a similar process occur before birth? Introducing Escherichia coli into the uterus late in gestation increases the likelihood of white matter damage in the fetal rabbit $(12,13)$ and rat $(14,15)$, although $E$. coli are not present in the brain. Introduction of noninfectious endotoxin (lipopolysaccharide) can also produce fetal white matter damage (16-18). Thus, an inflammationpromoting stimulus in the uterus can, without infecting the fetal brain, promote processes that lead to brain damage.

Intrauterine inflammatory processes also seem to increase the risk of white matter damage and CP in the human infant born very preterm $(19,20)$. Only indirect evidence supports the hypothesis that microorganisms isolated from the uterus increase the risk of white matter damage in extremely preterm infants (21-25). We now provide direct support.

\section{METHODS}

Additional details about the methods can be found in supplementary material (http://links.lww.com/PDR/A52). The Extremely Low Gestational Age Newborn (ELGAN) study was designed to identify characteristics and exposures that increase the risk of structural and functional neurologic disorders in ELGANs. During the years 2002 to 2004, 1249 mothers who gave birth to 1506 infants before the 28th week (1007 singletons, 414 twins, 77 triplets, two quadruplets, and six sextuplets) consented to participate (Fig. 1). The informed consent procedures and documents were approved by all 14 institutions that enrolled families for this study.

The sample for the brain ultrasound component of this report consists of the 1246 infants $(83 \%)$ whose placenta was biopsied under sterile conditions for cultures and submitted for histologic evaluation and who had one or more sets of protocol ultrasound scans of the brain read concordantly by two independent sonologists. The sample for the CP component is limited to the 899 children ( $88 \%$ of 1022 survivors) who also had a neurologic examination at 24-mo post-term equivalent.

The gestational age estimates were based on a hierarchy of the quality of available information. Most desirable were estimates based on the dates of embryo retrieval or intrauterine insemination or fetal ultrasound before the 14 th week $(62 \%)$. When these were not available, reliance was placed sequentially on a fetal ultrasound at 14 or more weeks $(29 \%)$, the first day of 


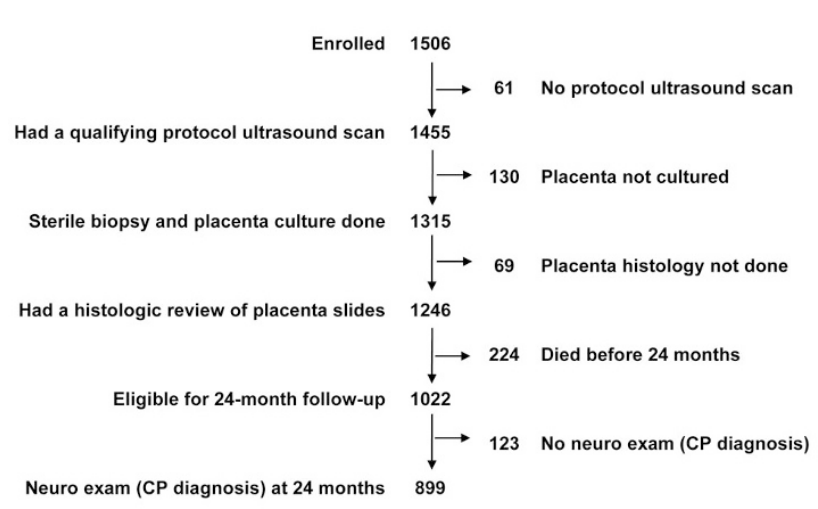

Figure 1. Sample description.

the last menstrual period (7\%), and gestational age recorded in the log of the neonatal intensive care unit $(1 \%)$.

Protocol scans. Ultrasound studies included six standard quasicoronal views and five sagittal views using the anterior fontanel as the sonographic window (26). The three sets of protocol scans were defined by the postnatal day on which they were obtained (1: days 1 to 4; 2: days 5 to 14 ; 3 : day 15 to wk 40). Details about the procedure and observer variability minimization efforts are presented elsewhere (27).

Placentas. The microbiologic procedures are described in detail elsewhere (28), as are details about histologic procedures (29).

24-mo developmental assessment. Procedures to standardize the neurologic examination and minimize examiner variability are presented elsewhere (30). The topographic diagnosis of CP (quadriparesis, diparesis, or hemiparesis) was based on an algorithm using these data (31).

Data analysis. We evaluated the following generalized null hypotheses: 1) the risk of an ultrasound lesion of the brain or a $\mathrm{CP}$ diagnosis is not associated with the recovery of microorganisms from placenta parenchyma; 2) the risk of an ultrasound lesion of the brain or a CP diagnosis is not associated with any histologic lesion of the placenta; and 3) microorganisms need not elicit histologic inflammation of the placenta to predict an abnormality on an ultrasound scan of the brain or a $\mathrm{CP}$ diagnosis.

In both the ultrasound-assessed sample $(n=1246)$ and in the developmentally assessed sample $(n=899)$, placentas delivered vaginally were more likely than placentas delivered by cesarean section to harbor a microorganism. Consequently, we evaluated our hypotheses first in the entire sample (Table 1 ), and then, in the subsamples of vaginal and cesarean section deliveries (Table 2 for ultrasound lesions and Table 3 for $\mathrm{CP}$ diagnoses).

Because ultrasound characteristics tended to occur together, we compared the placentas of infants whose ultrasound scans had a lesion to those of the 975 infants whose scans showed no abnormality. We created multivariable models to identify the contribution of relevant characteristics and exposures to the outcome of interest. Their contributions are presented as risk ratios with $95 \%$ CI. The only potential cofounders that modified the risk ratios were categories of gestational age (23-24, 25-26, 27 wk). Therefore, we adjusted for these variables only.

Because the $\mathrm{CP}$ diagnoses are mutually exclusive and each is appropriately compared with the same group of children without any $\mathrm{CP}$ diagnosis, we used multinomial logistic regression for analyses, presented in Tables 2 and 4. The logistic regression analyses for Table 5, however, are not multinomial, because the comparison group for each diagnosis consists of children whose placenta neither harbored an organism nor had histologic inflammation.

\section{RESULTS}

Placenta microbiology. Infants whose placenta harbored an aerobe or an anaerobe were at increased risk of ventriculomegaly, as were infants whose placenta harbored more than one organism or an organism considered part of normal skin flora (Table 1). Similar to ventriculomegaly, an echolucent lesion was associated with recovery of an aerobe, multiple organisms, and an organism considered part of normal skin flora. In contrast to ventriculomegaly, however, an echolucent lesion was associated with single organism cultures but not with recovery of an anaerobe.
Table 1. Sample description

\begin{tabular}{|c|c|c|c|c|c|c|c|c|}
\hline \multirow[b]{2}{*}{ Gestational age (wk) } & \multicolumn{4}{|c|}{ Vaginal deliveries } & \multicolumn{4}{|c|}{ Cesarean section } \\
\hline & $23-24$ & $25-26$ & 27 & $N$ & $23-24$ & $25-26$ & 27 & $N$ \\
\hline \multicolumn{9}{|l|}{ Microorganism } \\
\hline Any aerobe & 53 & 55 & 38 & 146 & 30 & 63 & 43 & 136 \\
\hline Any anaerobe & 41 & 52 & 35 & 128 & 36 & 59 & 31 & 126 \\
\hline Any Mycoplasma & 15 & 18 & 14 & 47 & 10 & 19 & 14 & 43 \\
\hline \multicolumn{9}{|l|}{ No. species } \\
\hline 0 & 17 & 59 & 28 & 104 & 47 & 164 & 148 & 359 \\
\hline 1 & 21 & 23 & 19 & 63 & 23 & 72 & 55 & 150 \\
\hline $2+$ & 46 & 55 & 36 & 137 & 30 & 38 & 18 & 86 \\
\hline Skin flora* & 33 & 37 & 31 & 101 & 15 & 32 & 28 & 75 \\
\hline Vagina flora $\dagger$ & 29 & 29 & 26 & 84 & 16 & 34 & 9 & 59 \\
\hline \multicolumn{9}{|l|}{ Histology } \\
\hline \multicolumn{9}{|l|}{ Inflammation } \\
\hline Chorionic plate $\ddagger$ & 31 & 48 & 22 & 101 & 20 & 32 & 20 & 72 \\
\hline Chorion/decidua§ & 48 & 77 & 42 & 167 & 34 & 78 & 40 & 152 \\
\hline Fetal stem vessel & 29 & 58 & 34 & 121 & 25 & 57 & 25 & 107 \\
\hline Umbilical cord\| & 15 & 36 & 20 & 71 & 16 & 40 & 18 & 74 \\
\hline Thrombosis FSV" & 5 & 7 & 7 & 19 & 1 & 13 & 12 & 26 \\
\hline Infarct & 12 & 21 & 16 & 49 & 13 & 47 & 54 & 111 \\
\hline$\uparrow$ syncytial knots & 12 & 14 & 11 & 37 & 19 & 56 & 71 & 146 \\
\hline Decidual deposition & 30 & 32 & 14 & 76 & 15 & 34 & 20 & 69 \\
\hline \multicolumn{9}{|l|}{ Delivery initiator } \\
\hline Preterm labor & 54 & 78 & 43 & 175 & 43 & 100 & 89 & 232 \\
\hline PPROM & 14 & 36 & 29 & 79 & 18 & 53 & 41 & 112 \\
\hline Preeclampsia & 1 & 1 & 2 & 4 & 9 & 56 & 52 & 117 \\
\hline Abruption & 11 & 10 & 6 & 27 & 15 & 36 & 20 & 71 \\
\hline $\mathrm{Cx}$ insufficiency & 4 & 9 & 3 & 16 & 12 & 15 & 3 & 30 \\
\hline Fetal indication & 0 & 3 & 0 & 3 & 3 & 14 & 16 & 33 \\
\hline \multicolumn{9}{|l|}{ Outcomes } \\
\hline Ventriculomegaly & 14 & 12 & 8 & 34 & 12 & 30 & 15 & 57 \\
\hline Echolucency & 11 & 17 & 3 & 31 & 8 & 12 & 12 & 32 \\
\hline \multicolumn{9}{|l|}{$\mathrm{CP}$} \\
\hline Quadriparesis & 10 & 10 & 2 & 22 & 13 & 8 & 10 & 31 \\
\hline Diparesis & 10 & 5 & 3 & 18 & 7 & 2 & 6 & 15 \\
\hline Hemiparesis & 5 & 3 & 0 & 8 & 1 & 5 & 3 & 9 \\
\hline Maximum column $(N)$ & 84 & 137 & 83 & 304 & 100 & 274 & 221 & 595 \\
\hline
\end{tabular}

These are the numbers of children who had the characteristics listed at the top of each row and in the left-hand column.

* Corynebacterium sp, Propionebacterium sp, Staphylococcus sp.

$\dagger$ Prevotella bivia, Lactobacillus sp, Peptostreptococcus magnus, and Gardnerella vaginalis.

$\$$ Stage 3 and severity 3 .

$\S$ Grades 3 and 4.

$\|$ Grades 3, 4, and 5.

Generally, vaginal and cesarean section subsamples provided similar information about associations between bacteria recovered from the placenta and ventriculomegaly (Table 2). On the other hand, much of the association between recovery of bacteria and an echolucent lesion in the cerebral white matter reflects the contribution of the cesarean section subsample. Statistical insignificance in the subsamples and significance in the total sample is a consequence of the consistent direction of the ORs in the subsamples and of the larger size of the total sample.

The only individual organism associated with increased risk of ventriculomegaly in infants delivered vaginally and in those delivered by cesarean section was Actinomyces species (Table S1; supplementary material, http://links.lww.com/PDR/A52). Only in infants delivered vaginally was Corynebacterium $\mathrm{sp}$ associated with an increased risk of ventriculomegaly. In contrast, an echolucent lesion was associated with recovery of Pro- 
Table 2. ORs (95\% CI) of two ultrasound lesions (ventriculomegaly and an echolucent white matter lesion) and three CP diagnoses (quadriparesis, diparesis, and hemiparesis) associated with each placental organism or group of organisms listed on the left

\begin{tabular}{|c|c|c|c|c|c|}
\hline \multirow[b]{2}{*}{ Microorganism } & \multicolumn{2}{|c|}{ Ultrasound lesion } & \multicolumn{3}{|c|}{ Type of CP } \\
\hline & Ventriculomegaly & Echolucent lesion & Quadriparesis & Diparesis & Hemiparesis \\
\hline Any aerobe & $1.7(1.2-2.4)$ & $1.5(1.01-2.4)$ & $1.6(0.9-2.8)$ & $4.0(1.9-8.6)$ & $0.6(0.2-2.0)$ \\
\hline Any anaerobe & $1.5(1.02-2.1)$ & $1.3(0.9-2.1)$ & $1.9(1.1-3.4)$ & $1.7(0.8-3.4)$ & $1.0(0.3-2.9)$ \\
\hline Any Mycoplasma & $1.0(0.6-1.7)$ & $1.1(0.6-2.1)$ & $0.9(0.3-2.3)$ & $2.2(0.9-5.3)$ & $0.5(0.1-4.1)$ \\
\hline \multicolumn{6}{|l|}{ No. species } \\
\hline 1 & $1.5(0.9-2.3)$ & $1.8(1.1-3.0)$ & $1.2(0.6-2.6)$ & $3.4(1.2-9.6)$ & $0.6(0.2,2.3)$ \\
\hline $2+$ & $1.9(1.2-2.8)$ & $1.9(1.1-3.1)$ & $2.3(1.2-4.4)$ & $5.2(2.0-14)$ & $0.8(0.2,2.5)$ \\
\hline Skin flora* & $1.7(1.2-2.5)$ & $2.1(1.3-2.2)$ & $1.4(0.7-2.7)$ & $2.5(1.2-5.2)$ & $0.3(0-2.0)$ \\
\hline Vaginal flora $\dagger$ & $1.1(0.7-1.7)$ & $1.0(0.6-1.7)$ & $1.3(0.7-2.7)$ & $1.4(0.6-3.3)$ & $0.3(0-2.2)$ \\
\hline
\end{tabular}

These data are from the total sample. The only adjustment is for gestational age (23-24, 25-26, and $27 \mathrm{wk})$.

* Corynebacterium sp, Propionebacterium sp, and Staphylococcus sp.

$\dagger$ Prevotella bivia, Lactobacillus sp, Peptostreptococcus magnus, and Gardnerella vaginalis.

Table 3. ORs (95\% CI) of ventriculomegaly and an echolucent white matter lesion associated with each placental organism or group of organisms listed on the left in the vaginal and cesarean section delivery subsamples

\begin{tabular}{|c|c|c|c|c|}
\hline \multirow[b]{2}{*}{ Microorganism } & \multicolumn{2}{|c|}{ Ventriculomegaly } & \multicolumn{2}{|c|}{ Echolucent lesion } \\
\hline & Vaginal & Cesarean & Vaginal & Cesarean \\
\hline Any aerobe & $1.7(0.98-3.0)$ & $1.4(0.9-2.4)$ & $0.9(0.5-1.7)$ & $1.9(1.04-3.6)$ \\
\hline Any anaerobe & $1.2(0.7-2.0)$ & $1.6(0.9-2.6)$ & $1.1(0.6-2.0)$ & $1.4(0.7-2.7)$ \\
\hline Any Mycoplasma & $1.0(0.5-1.9)$ & $0.8(0.3-2.0)$ & $0.7(0.3-1.7)$ & $1.5(0.6-4.0)$ \\
\hline \multicolumn{5}{|c|}{ No. species } \\
\hline 1 & $1.9(0.9-4.2)$ & $1.2(0.7-2.2)$ & $1.4(0.6-3.3)$ & $2.0(1.01-3.9)$ \\
\hline $2+$ & $1.8(0.9-3.5)$ & $1.9(1.02-3.4)$ & $1.2(0.6-2.5)$ & $2.0(0.9-2.4)$ \\
\hline Skin flora* & $1.5(0.9-2.5)$ & $1.8(0.99-3.2)$ & $1.1(0.6-2.0)$ & $3.5(1.8-6.7)$ \\
\hline Vaginal flora $\uparrow$ & $1.1(0.6-1.9)$ & $0.9(0.4-1.9)$ & $0.7(0.3-1.4)$ & $1.3(0.5-3.2)$ \\
\hline
\end{tabular}

Table 4. ORs (95\% CI) of a CP diagnosis of quadriparesis or diparesis associated with each placental organism or group of organisms listed on the left in the vaginal and cesarean section delivery subsamples

\begin{tabular}{lcclll}
\hline \multirow{2}{*}{ Microorganism } & \multicolumn{2}{c}{ Quadriparesis } & & \multicolumn{2}{c}{ Diparesis } \\
\cline { 2 - 3 } \cline { 5 - 6 } \cline { 5 - 6 } & Vaginal & Cesarean & & Vaginal & Cesarean \\
\hline Any aerobe & $1.3(0.5-3.2)$ & $1.8(0.8-4.0)$ & & $5.1(1.4-18)$ & $3.0(1.03-8.5)$ \\
Any anaerobe & $2.8(1.1-7.0)$ & $1.4(0.6-3.2)$ & & $3.0(1.1-8.5)$ & $0.4(0.1-2.0)$ \\
Any Mycoplasma & $0.8(0.2-2.8)$ & $0.9(0.2-4.0)$ & & $0.9(0.3-3.5)$ & $4.7(1.4-16)$ \\
No. species & & & & & \\
$\quad 1$ & $0.8(0.3-2.5)$ & $0.8(0.2-3.3)$ & & $1.1(0.3-3.9)$ & $0.3(0,2.7)$ \\
$2+$ & $2.5(0.5-14)$ & $1.9(0.3-11)$ & & $2.0(0.3-15)$ & $7.8(0.6,98)$ \\
Skin flora* & $1.5(0.6-3.7)$ & $1.3(0.5-3.5)$ & & $3.1(1.1-8.5)$ & $1.0(0.2-4.6)$ \\
Vaginal flora $\dagger$ & $1.5(0.6-3.8)$ & $1.2(0.4-3.7)$ & & $1.2(0.4-3.3)$ & $1.3(0.3-6.3)$ \\
\hline
\end{tabular}

The only adjustment is for gestational age (23-24, 25-26, and $27 \mathrm{wk})$.

* Corynebacterium sp, Propionebacterium sp, and Staphylococcus sp.

$\dagger$ Prevotella bivia, Lactobacillus sp, Peptostreptococcus magnus, and Gardnerella vaginalis.

pionibacterium sp, nonaureus Staphylococcus sp, and Gardnerella vaginalis, but only in the cesarean section subsample (Table S2; supplementary material, http://links.lww.com/PDR/A52).

In the total sample, the risk of quadriparesis was increased if an anaerobe or multiple organisms were recovered from the placenta (Table 1). The odds of diparesis, on the other hand, were increased if the placenta harbored an aerobe, a single organism, multiple organisms, or an organism considered part of normal skin flora. Hemiplegic $\mathrm{CP}$ was not associated with any organism.

The vaginal subsample contributed appreciably to the associations seen in the total sample for quadriparetic and diparetic CP (Table 3). In the cesarean section delivered subsample, the association between quadriparetic $\mathrm{CP}$ and an anaerobe was hardly evident, whereas the association between quadriparetic $\mathrm{CP}$ and polymicrobial infections was less prominent than in the vaginal subsample. In contrast, cesarean section delivered placentas provided much of the information about the increased risk of diparesis associated with Mycoplasma sp and polymicrobial infections, and none of the information about an increased risk associated with skin organisms.

Diparesis was associated with recovery of Corynebacterium sp and nonaureus Staphylococcus in the total sample (Table S3; supplementary material, http://links.lww.com/PDR/A52). The association between Corynebacterium $\mathrm{sp}$ and diparesis was statistically significant only among vaginally delivered placenta/child dyads (Table S4; supplementary material, http://links.lww.com/PDR/A52). Among those delivered by cesarean section, diparesis was statistically significantly associated with both alpha hemolytic Streptococcus and Mycoplasma sp (Table S5; supplementary material, http:// links.lww.com/PDR/A52).

Placenta histologic characteristics. Inflammation of the chorionic plate and the chorion/decidua, and thrombosis of the fetal stem vessels were associated with increased risk of ventriculomegaly, whereas a placenta infarct was associated with reduced risk (Table 3). An echolucent lesion, on the other hand, was associated only with decidual hemorrhage and fibrin deposition considered indicative of abruption. Vaginal and cesarean section delivered placentas conveyed similar histologic information about the risk of ultrasound lesions (Table S6; supplementary material, http://links.lww.com/ PDR/A52).

Inflammation of the chorionic plate and the chorion/decidua were associated with an increased risk of the diparetic form of CP (Table 4). Here, too, both vaginal and cesarean section subsamples contributed to this increased risk.

Need organisms that promote visible placenta inflammation to influence risks? Totally, $32 \%$ of inflamed placentas (155 of 488) did not harbor a microorganism, whereas $39 \%$ of 
Table 5. ORs (95\% CI) of two ultrasound lesions (ventriculomegaly and an echolucent white matter lesion) and three CP diagnoses (quadriparesis, diparesis, and hemiparesis) associated with each placenta histologic characteristic listed on the left

\begin{tabular}{|c|c|c|c|c|c|}
\hline \multirow[b]{2}{*}{ Microorganism } & \multicolumn{2}{|c|}{ Ultrasound lesion } & \multicolumn{3}{|c|}{ Type of CP } \\
\hline & Ventriculomegaly & Echolucent lesion & Quadriparesis & Diparesis & Hemiparesis \\
\hline Inflammation chorionic plate* & $1.5(1.02-2.3)$ & $1.6(0.97-2.5)$ & $1.6(0.9-3.0)$ & $2.3(1.1-4.8)$ & $2.2(0.8-6.1)$ \\
\hline Inflammation chorion/decidua $\dagger$ & $1.4(1.01-2.4)$ & $1.3(0.8-2.0)$ & $1.6(0.9-2.9)$ & $3.4(1.6-7.4)$ & $1.2(0.5-3.2)$ \\
\hline Neutrophils in fetal stem vessls & $1.4(0.99-2.1)$ & $1.4(0.9-2.1)$ & $1.4(0.8-2.8)$ & $1.7(0.8-3.7)$ & $1.3(0.4-3.7)$ \\
\hline Umbilical cord vasculitis $\ddagger$ & $1.4(0.9-2.2)$ & $0.8(0.4-1.5)$ & $1.5(0.8-3.0)$ & $1.7(0.8-3.5)$ & $0.8(0.3-2.6)$ \\
\hline Thrombosis fetal stem vessels & $2.1(1.2-3.9)$ & $1.6(0.7-3.4)$ & $1.2(0.6-2.7)$ & $1.9(0.8-4.3)$ & $1.6(0.5-5.2)$ \\
\hline Infarct & $0.5(0.3-0.96)$ & $1.0(0.6-1.8)$ & $1.9(0.6-5.5)$ & $1.5(0.3-6.6)$ & $1.4(0.2-11)$ \\
\hline Increased syncytial knots & $0.7(0.5-1.2)$ & $0.9(0.5-1.5)$ & $1.7(0.9-3.5)$ & $0.7(0.2-2.1)$ & $1.1(0.3-3.9)$ \\
\hline Decidual hem/fibrin deposition & $1.0(0.6-1.5)$ & $1.7(1.03-2.8)$ & $1.0(0.5-2.0)$ & $0.5(0.2-1.5)$ & $0.3(0-2.0)$ \\
\hline
\end{tabular}

These data are from the total sample. The only adjustment is for gestational age (23-24, 25-26, and 27 wk).

* Stage 3 and severity 3.

$\uparrow$ Grades 3 and 4.

$\$$ Grades 3, 4, and 5 .

Table 6. ORs (95\% CI) of ventriculomegaly and an echolucent lesion, as well as each CP diagnosis, among children whose placenta had the characteristics listed on the left relative to the risk among children whose placenta harbored no recoverable organism and had no histologic lesion considered indicative of inflammation

\begin{tabular}{|c|c|c|c|c|c|c|}
\hline \multirow[b]{2}{*}{ Organism } & \multirow[b]{2}{*}{ Placenta lesion* } & \multicolumn{2}{|c|}{ Ultrasound lesion } & \multicolumn{3}{|c|}{ Type of CP } \\
\hline & & Ventriculomegaly & Echolucency & Quadriparesis & Diparesis & Hemiaresis \\
\hline+ & + & $2.5(1.1-5.7)$ & $1.7(0.6-4.8)$ & $1.5(0.4-5.5)$ & $0.8(0.1-4.7)$ & $3.5(0.4-34)$ \\
\hline+ & - & $1.2(0.7-1.9)$ & $1.5(0.8-2.6)$ & $1.4(0.6-3.1)$ & $4.0(1.04-16)$ & $0.4(0.1-1.8)$ \\
\hline- & + & $0.6(0.3-1.2)$ & $0.7(0.3-1.7)$ & $0.9(0.3-27)$ & $2.8(0.6-14)$ & $0.6(0.1-3.0)$ \\
\hline- & - & 1.0 & 1.0 & 1.0 & 1.0 & 1.0 \\
\hline
\end{tabular}

Adjusted for gestational age (23-24, 25-26, and $27 \mathrm{wk})$.

* Placenta lesions considered indicative of inflammation are inflammation of chorionic plate stage 3 and severity 3 , inflammation of chorion/decidua grades 3 and 4, neutrophilic infiltration of fetal stem vessels, and umbilical cord vasculitis grades 3,4 , and 5 .

noninflamed placentas (298 of 758) harbored a microorganism. In the entire sample (Table 5) and in the vaginal-delivery subsample (Table S7; supplementary material, http:// links.lww.com/PDR/A52), the risk of ventriculomegaly was higher when recovery of an organism was accompanied by histologic inflammation than when either characteristic occurred alone. In the cesarean section subsample, the modestly increased risk of ventriculomegaly associated with recovery of an organism was not influenced by the presence of an inflammatory lesion in the placenta. No histologic placenta lesion predicted an echolucent lesion better when an organism was recovered than when it was not.

In the total sample (Table 6), as well as in the cesarean section subsample (Table S8; supplementary material, http:// links.lww.com/PDR/A52), the risk of diparetic CP was most prominently increased when recovery of an organism was unaccompanied by an inflammatory placenta lesion.

\section{DISCUSSION}

Summary of key findings. We studied ultrasound lesions because they are the earliest readily evident indicators of brain damage in the preterm newborn. They are also less likely than later manifestations of brain damage, such as $\mathrm{CP}$, to be influenced by postnatal exposures.

A number of our findings are entirely new. First, the recovery of relatively low-virulence microorganisms from the placenta predicted both forms of cerebral white matter damage (ventriculomegaly and an echolucent lesion). Some of the organisms considered typical skin microflora in healthy individuals (e.g., Propionebacterium sp, Corynebacterium sp, and nonaureus Staphylococcus sp) were recovered even from placentas delivered by cesarean section, which are the ones least likely to be "contaminated." Second, the recovery of microorganisms from the placenta predicted quadriparetic and diparetic forms of CP. Third, polymicrobial infections seem to be biologically important in the pathogenesis of white matter damage and later CP. Fourth, membrane inflammation predicted both ventriculomegaly and diparetic CP. Fifth, the microorganisms did not have to elicit an inflammatory histologic response in the placenta to retain their association with diparetic CP. Finally, the risk of ventriculomegaly was heightened by the combination of organism recovery and histologic inflammation.

Influence of route of delivery. We analyzed the microbiologic data in the entire sample and in the subsamples defined by the route of delivery. This enabled us to explore whether phenomena associated with route of delivery modified the association between placenta colonization or infection and ultrasound abnormalities, as well as CP diagnoses. Such effect modification seems plausible for two reasons. First, bacteria recovered from placentas delivered vaginally might reflect contamination during the delivery process; such contamination is less likely with abdominal delivery (28). Second, the higher rate of bacterial colonization in placentas delivered vaginally might reflect the processes leading to vaginal delivery (e.g., preterm labor; 32) and the effects of repeated digital 
cervical examinations (33). Placentas delivered by cesarean section are less likely to be affected by these processes and, therefore, may be considered a "cleaner" sample.

In some situations, the vaginal delivery subsample and the cesarean section subsample provided similar information. For example, the risk of ventriculomegaly associated with multispecies cultures in the vaginal delivery subsample $[\mathrm{OR}=1.8$ $(0.9-3.5)$ ] was very similar to the risk in the cesarean section subsample: $[\mathrm{OR}=1.9(1.02-3.4)]$. In other situations, the divergence is prominent. For example, the recovery of skin flora organisms was more prominently associated with an echolucent lesion in the cesarean section subsample, whereas the association with diparetic $\mathrm{CP}$ was more prominent in the vaginal subsample.

Low-virulence organisms. The nonpregnant uterus often harbors microorganisms (34). Their biologic significance remains unclear, but the mere presence of bacteria in the nonpregnant uterus raises the possibility that some of the tendency of the pregnant uterus to harbor microorganisms might not differ substantially from the propensity of the nonpregnant uterus to harbor microorganisms. On the other hand, the immunologic suppression that contributes to tolerance of the fetus might allow greater numbers of microorganisms in the gravid uterus than in the nongravid uterus for long periods of time without clinical manifestations (35).

In contrast, we believe several observations suggest that some of the organisms in the pregnant uterus are biologically important. First, the proportion of placentas that harbored bacteria varies with the indication for preterm delivery. The recovery rate ranges from a low of $25 \%$ among cesarean section-delivered placentas of women who had preeclampsia to $79 \%$ among placentas of women who had preterm labor at 23 wk (28). Second, among placentas from pregnancies that ended with preterm labor, the prevalence of microorganisms decreases with increasing age $(28,36)$. Third, organisms are preferentially recovered from placentas that have high-grade chorionic plate inflammation and/or fetal vasculitis (neutrophilic infiltration of chorionic plate fetal stem vessels or umbilical cord vessels) (28). Although some of these are high-virulence organisms, some are low-virulence organisms associated with ventriculomegaly and diparesis. Others have detected bacterial DNA in human fetal membranes, even in the absence of histologic inflammation (37).

The multiplicity of relatively low-virulence microorganisms associated with white matter damage and CP suggests that the stimulus for the brain damage is not specific. Some low-virulence microorganisms are more likely to produce disease when in the presence of other low-virulence organisms than when alone (38). Thus, the polymicrobial cultures need not indicate contamination. Indeed, the co-occurrence of multiple low-virulence organisms might explain how they contribute to brain damage.

In our sample, Mycoplasma organisms were associated with an increased risk of diparetic CP but only in the cesarean section subsample. This very limited association calls into question its biologic significance. Nevertheless, a previous study linked Mycoplasma in the placenta with an increased risk of white matter damage in low birth weight newborns
(39), and a more recent report found that preterm infants whose amniotic fluid harbored Ureaplasma urealyticum were at increased risk for $\mathrm{CP}(40)$.

The distinctiveness of diparetic $\mathrm{CP}$. $\mathrm{CP}$ occurs much more commonly in children born before $28 \mathrm{wk}$ than in those born at term (41). Some of the higher prevalence in children born months before term reflects the preferential occurrence of diparesis $(42,43)$. Although the vulnerability of preterm-born children for diparetic CP might be because of the vulnerability of paraventricular white matter, the possibility that inflammatory phenomena associated with preterm delivery contribute to the occurrence of diparetic $\mathrm{CP}$ is supported by our finding that diparetic CP was predicted by recovery of a single microorganism, skin flora, and polymicrobial cultures, as well as by histologic inflammation of the placenta, even when an organism was not recovered.

We created an algorithm for diagnosing three clinically distinguishable CP types (31). The observation that diparesis is the $\mathrm{CP}$ diagnosis most clearly associated with inflammatory phenomena supports our view that different forms of CP differ in some of their antecedents.

Our finding of an association between histologic inflammation and diparetic $\mathrm{CP}$ is new. Thrombosis of fetal stem vessels predicted ventriculomegaly in this study and predicted $\mathrm{CP}$ and other neurodisabilities in another study (44). In that study, "Chorionic plate thrombi were seen only with chorioamnionitis and accounted for the increased risk of neurologic impairment seen with chorioamnionitis." We, too, have found that fetal stem vessel thrombosis occurs preferentially in inflamed placentas, but not exclusively (29).

Evolution of the inflammation hypothesis of cerebral white matter pathogenesis in the newborn. The hypothesis that bacteria can contribute to white matter damage and $\mathrm{CP}$ without entering the brain, first raised more than $30 \mathrm{y}$ ago (5), has been supported and expanded by subsequent reports. First, cytokines are among the noninfectious circulating products of infection that seem to mediate white matter damage and CP (20). Second, the inflammation can begin before birth (11). Third, both innate and adaptive immune systems are probably also involved in white matter damage (45).

The two-hit hypothesis of cerebral white matter damage finds support from observations in immature animals that early exposures to inflammatory factors can increase the susceptibility of the brain to subsequent insults (sensitization) $(46,47)$ and, under slightly different circumstances, reduce the susceptibility of the brain to subsequent insults (preconditioning) (48). Our finding that the risk of ventriculomegaly is heightened when the placenta not only harbors an organism but is also histologically inflamed might be an instance of sensitization.

The findings reported here support this view of inflammation-induced damage. The observation that placenta organisms convey risk information about brain damage in the offspring supports the hypothesis that some brain damage in the preterm newborn has its origins in utero. This observation also supports the hypothesis that some of the brain damage is initiated by bacteria, some of which can be typical skin microflora or other low-virulence microorganisms. 
We previously suggested that the fetal inflammatory response to intrauterine infection might have two stages (11). Others have found support for this view (49). The initial stage, evident before histologic chorioamnionitis is identifiable, might be characterized by the synthesis of early cytokines by fetal endothelial cells. The second stage, accompanied by histologic inflammation of the placenta and umbilical cord, might be characterized by a stronger expression of later cytokines. Because we do not yet have information about circulating cytokines, we do not know when the first stage occurred in any of the children in our sample.

The risk of diparetic CP was increased in infants whose placenta was inflamed (Table 4) and in infants whose placenta harbored an organism without any accompanying placenta inflammation (Table 5). These observations raise the possibility that some of the placenta inflammation among children who developed diparesis was initiated by something other than a readily cultured and identified bacterium, such as a fastidious bacterium or a noninfectious stimulus (50).

The risk of ventriculomegaly was heightened by the joint occurrence of organism presence in the placenta and histologic inflammation of the placenta. The risk of diparetic $\mathrm{CP}$, however, was increased in infants whose placenta was inflamed (Table 4), and in infants whose placenta harbored an organism, but without any further increase if the infant had both characteristics (Table 5). These observations raise the possibility that some of the placenta inflammation among children who developed diparesis was stimulated by something other than a bacterium.

In conclusion, extremely preterm infants whose placentas harbor low-virulence microorganisms seem to be at increased risk of cerebral white matter damage and $\mathrm{CP}$. These findings are strong support for antenatal infectious contributions to perinatal white matter damage and its correlates. Our findings also suggest that histologic inflammation of the placenta is not an essential intermediary between microorganism presence and the development of diparetic CP and that biologically significant inflammation of the placenta can occur in the absence of a recoverable microorganism.

\section{REFERENCES}

1. Msall ME 2004 Developmental vulnerability and resilience in extremely preterm infants. JAMA 292:2399-2401

2. Marlow N, Wolke D, Bracewell MA, Samara M 2005 Neurologic and developmental disability at six years of age after extremely preterm birth. N Engl J Med 352:9-19

3. Hack M, Klein N 2006 Young adult attainments of preterm infants. JAMA 295:695696

4. O’Shea TM, Counsell SJ, Bartels DB, Dammann O 2005 Magnetic resonance and ultrasound brain imaging in preterm infants. Early Hum Dev 81:263-271

5. Leviton A, Gilles F, Neff R, Yaney P 1976 Multivariate analysis of risk of perinatal telencephalic leucoencephalopathy. Am J Epidemiol 104:621-626

6. Inder TE, Wells SJ, Mogridge NB, Spencer C, Volpe JJ 2003 Defining the nature of the cerebral abnormalities in the premature infant: a qualitative magnetic resonance imaging study. J Pediatr 143:171-179

7. Shah DK, Doyle LW, Anderson PJ, Bear M, Daley AJ, Hunt RW, Inder TE 2008 Adverse neurodevelopment in preterm infants with postnatal sepsis or necrotizing enterocolitis is mediated by white matter abnormalities on magnetic resonance imaging at term. J Pediatr 153:170-175, 175.e171

8. Stoll BJ, Hansen NI, Adams-Chapman I, Fanaroff AA, Hintz SR, Vohr B, Higgins RD 2004 Neurodevelopmental and growth impairment among extremely low-birthweight infants with neonatal infection. JAMA 292:2357-2365

9. Glass HC, Bonifacio SL, Chau V, Glidden D, Poskitt K, Barkovich AJ, Ferriero DM, Miller SP 2008 Recurrent postnatal infections are associated with progressive white matter injury in premature infants. Pediatrics 122:299-305
10. Gilles FH, Gomez IG 2005 Developmental neuropathology of the second half of gestation. Early Hum Dev 81:245-253

11. Dammann O, Leviton A 2000 Role of the fetus in perinatal infection and neonatal brain damage. Curr Opin Pediatr 12:99-104

12. Yoon BH, Kim CJ, Romero R, Jun JK, Park KH, Choi ST, Chi JG 1997 Experimentally induced intrauterine infection causes fetal brain white matter lesions in rabbits. Am J Obstet Gynecol 177:797-802

13. Debillon T, Gras-Leguen C, Leroy S, Caillon J, Roze JC, Gressens P 2003 Patterns of cerebral inflammatory response in a rabbit model of intrauterine infectionmediated brain lesion. Brain Res Dev Brain Res 145:39-48

14. Rodts-Palenik S, Wyatt-Ashmead J, Pang Y, Thigpen B, Cai Z, Rhodes P, Martin JN, Granger J, Bennett WA 2004 Maternal infection-induced white matter injury is reduced by treatment with interleukin-10. Am J Obstet Gynecol 191:13871392

15. Yuan TM, Yu HM, Gu WZ, Li JP 2005 White matter damage and chemokine induction in developing rat brain after intrauterine infection. J Perinat Med 33:415422

16. Gilles FH, Leviton A, Kerr CS 1976 Endotoxin leucoencephalopathy in the telencephalon of the newborn kitten. J Neurol Sci 27:183-191

17. Bell MJ, Hallenbeck JM 2002 Effects of intrauterine inflammation on developing rat brain. J Neurosci Res 70:570-579

18. Kannan S, Saadani-Makki F, Muzik O, Chakraborty P, Mangner TJ, Janisse J, Romero R, Chugani DC 2007 Microglial activation in perinatal rabbit brain induced by intrauterine inflammation: detection with 11C-(R)-PK11195 and small-animal PET. J Nucl Med 48:946-954

19. Wu YW 2002 Systematic review of chorioamnionitis and cerebral palsy. Ment Retard Dev Disabil Res Rev 8:25-29

20. Dammann O, O'Shea TM 2008 Cytokines and perinatal brain damage. Clin Perinatol 35:643-663, v

21. Romero R, Espinoza J, Goncalves LF, Kusanovic JP, Friel L, Hassan S 2007 The role of inflammation and infection in preterm birth. Semin Reprod Med 25:21-39

22. Murthy V, Kennea NL 2007 Antenatal infection/inflammation and fetal tissue injury. Best Pract Res Clin Obstet Gynaecol 21:479-489

23. Hagberg H, Mallard C, Jacobsson B 2005 Role of cytokines in preterm labour and brain injury. BJOG 112:16-18

24. Edwards AD, Tan S 2006 Perinatal infections, prematurity and brain injury. Curr Opin Pediatr 18:119-124

25. Redline RW, Minich N, Taylor HG, Hack M 2007 Placental lesions as predictors of cerebral palsy and abnormal neurocognitive function at school age in extremely low birth weight infants $(<1 \mathrm{Kg})$. Pediatr Dev Pathol 10:282-292

26. Teele R, Share J 1991 Ultrasonography of infants and children. Saunders, Philadelphia, PA

27. Kuban K, Adler I, Allred EN, Batton D, Bezinque S, Betz BW, Cavenagh E, Durfee S, Ecklund K, Feinstein K, Fordham LA, Hampf F, Junewick J, Lorenzo R, McCauley R, Miller C, Seibert J, Specter B, Wellman J, Westra S, Leviton A 2007 Observer variability assessing US scans of the preterm brain: the ELGAN study. Pediatr Radiol 37:1201-1208

28. Onderdonk AB, Hecht JL, McElrath TF, Delaney ML, Allred EN, Leviton A; ELGAN Study Investigators 2008 Colonization of second-trimester placenta parenchyma. Am J Obstet Gynecol 199:52.e1-52.e10

29. Hecht JL, Allred EN, Kliman HJ, Zambrano E, Doss BJ, Husain A, Pflueger SM, Chang CH, Livasy CA, Roberts D, Bhan I, Ross DW, Senagore PK, Leviton A; ELGAN Study Investigators 2008 Histological characteristics of singleton placentas delivered before the 28th week of gestation. Pathology 40:372-376

30. Kuban KC, O'Shea M, Allred E, Leviton A, Gilmore H, DuPlessis A, Krishnamoorthy K, Hahn C, Soul J, O'Connor SE, Miller K, Church PT, Keller C, Bream R, Adair R, Miller A, Romano E, Bassan H, Kerkering K, Engelke S, Marshall D, Milowic K, Wereszczak J, Hubbard C, Washburn L, Dillard R, Heller C, Burdo-Hartman W, Fagerman L, Sutton D, Karna P, Olomu N, Caldarelli L, Oca M, Lohr K, Scheiner A 2005 Video and CD-ROM as a training tool for performing neurologic examinations of 1-year-old children in a multicenter epidemiologic study. J Child Neurol 20:829-831

31. Kuban KC, Allred EN, O'Shea M, Paneth N, Pagano M, Leviton A; ELGAN Study Cerebral Palsy-Algorithm Group 2008 An algorithm for identifying and classifying cerebral palsy in young children. J Pediat 153:466-472

32. Goldenberg RL, Culhane JF, Iams JD, Romero R 2008 Epidemiology and causes of preterm birth. Lancet 371:75-84

33. Alexander JM, Mercer BM, Miodovnik M, Thurnau GR, Goldenberg RL, Das AF, Meis PJ, Moawad AH, Iams JD, Vandorsten JP, Paul RH, Dombrowski MP Roberts JM, McNellis D 2000 The impact of digital cervical examination on expectantly managed preterm rupture of membranes. Am J Obstet Gynecol 183:1003-1007

34. Andrews WW, Goldenberg RL, Hauth JC, Cliver SP, Conner M, Goepfert AR 2005 Endometrial microbial colonization and plasma cell endometritis after spontaneous or indicated preterm versus term delivery. Am J Obstet Gynecol 193:739-745

35. Redline RW, Lu CY 1987 Role of local immunosuppression in murine fetoplacental listeriosis. J Clin Invest 79:1234-1241

36. DiGiulio DB, Romero R, Amogan HP, Kusanovic JP, Bik EM, Gotsch F, Kim CJ, Erez O, Edwin S, Relman DA 2008 Microbial prevalence, diversity and abundance in amniotic fluid during preterm labor: a molecular and culture-based investigation. PLoS One 3:e3056

37. Steel JH, Malatos S, Kennea N, Edwards AD, Miles L, Duggan P, Reynolds PR, Feldman RG, Sullivan MH 2005 Bacteria and inflammatory cells in fetal membranes do not always cause preterm labor. Pediatr Res 57:404-411 
38. Brogden KA, Guthmiller JM, Taylor CE 2005 Human polymicrobial infections. Lancet 365:253-255

39. Dammann O, Allred EN, Genest DR, Kundsin RB, Leviton A 2003 Antenatal mycoplasma infection, the fetal inflammatory response and cerebral white matter damage in very-low-birthweight infants. Paediatr Perinat Epidemiol 17:49-57

40. Berger A, Witt A, Haiden N, Kaider A, Klebermasz K, Fuiko R, Langgartner M, Pollak A 2009 Intrauterine infection with Ureaplasma species is associated with adverse neuromotor outcome at 1 and 2 years adjusted age in preterm infants. J Perinat Med 37:72-78

41. Hagberg B, Hagberg G, Olow I, von Wendt L 1996 The changing panorama of cerebral palsy in Sweden. VII. Prevalence and origin in the birth year period 1987-90. Acta Paediatr 85:954-960

42. Vohr BR, Msall ME, Wilson D, Wright LL, McDonald S, Poole WK 2005 Spectrum of gross motor function in extremely low birth weight children with cerebral palsy at 18 months of age. Pediatrics 116:123-129

43. Robertson CM, Watt MJ, Yasui Y 2007 Changes in the prevalence of cerebral palsy for children born very prematurely within a population-based program over 30 years. JAMA 297:2733-2740
44. Redline RW, Wilson-Costello D, Borawski E, Fanaroff AA, Hack M 1998 Placental lesions associated with neurologic impairment and cerebral palsy in very low-birthweight infants. Arch Pathol Lab Med 122:1091-1098

45. Leviton A, Dammann O, Durum SK 2005 The adaptive immune response in neonatal cerebral white matter damage. Ann Neurol 58:821-828

46. Dommergues MA, Patkai J, Renauld JC, Evrard P, Gressens P 2000 Proinflammatory cytokines and interleukin-9 exacerbate excitotoxic lesions of the newborn murine neopallium. Ann Neurol 47:54-63

47. Eklind S, Mallard C, Arvidsson P, Hagberg H 2005 Lipopolysaccharide induces both a primary and a secondary phase of sensitization in the developing rat brain. Pediatr Res 58:112-116

48. Mallard C, Hagberg H 2007 Inflammation-induced preconditioning in the immature brain. Semin Fetal Neonatal Med 12:280-286

49. Romero R, Espinoza J, Goncalves LF, Kusanovic JP, Friel LA, Nien JK 2006 Inflammation in preterm and term labour and delivery. Semin Fetal Neonatal Med 11:317-326

50. Di Virgilio F, Ceruti S, Bramanti P, Abbracchio MP 2009 Purinergic signalling in inflammation of the central nervous system. Trends Neurosci 32:79-87 